\title{
Biology, Life Cycle and Damage Potential of Scutellera nobilis (Fabricius) (Hemiptera: Scutellaridae) on Jatropha curcas L. in Jammu (J\&K), India
}

\author{
Neha Jamwal*, Sanjay Bhatia, Kritika Raina \\ Department of Zoology, University of Jammu, India
}

Received February 11, 2020; Revised March 6, 2020; Accepted March 19, 2020

Copyright@2020 by authors, all rights reserved. Authors agree that this article remains permanently open access under the terms of the Creative Commons Attribution License 4.0 International License

\begin{abstract}
A native species of Mexico and tropical America, Jatropha curcas L. (Euphorbiaceae) is a perennial, multipurpose and drought resistant species, which is gaining importance commercially as a bio-diesel plant and is being intensively advocated for development of wastelands and dry lands throughout India. Contrary to the popular belief that toxicity of Jatropha curcas is sufficient deterrent for insects, several insect groups have overcome this barrier. Studies undertaken in Jammu revealed that Scutellera nobilis (Fabricius) (Hemiptera: Scutellaridae) causes extensive damage to Jatropha plantations. Various aspects of biology, life cycle and ecology of Scutellera nobilis were studied at Jammu, which revealed that the pest population remains abundant from April till November in the study area and the total life cycle of the pest lasts for about 30 - 36 days. This data can be used to keep the pest population in check, thereby, preventing the loss to plantation and to the economy on the whole. Being sap suckers, they feed upon all plant parts likely, but growing shoots and developing fruit are preferred resulting in the production of malformed and hollowed seeds. The feeding also leads to necrosis of the leaves and premature leaf fall. The present paper records first ever report on the biology and life cycle of Scutellera nobilis from Jammu region, which is an aim to design preventive measures against this pest to save the Jatropha plantations from being degraded.
\end{abstract}

Keywords Jatropha curcas, Scutellera nobilis, Biology, Damage Potential

\section{Introduction}

Jatropha curcas L. (Euphorbiaceae) is the most primitive species within an approximately known 165-175 species and is a native of Mexico and tropical America which is being commercialized as a bio-diesel plant throughout the world because of its oil producing capability [1,3]. A drought resistant, hardy species has now naturalized throughout the tropical regions of the world and produces seeds with an oil content of $37 \%$ that can be transformed into bio- diesel fuel through esterification [11] and can act as a good fuelwood substitute [10].

Jatropha curcas is under trial plantations in Jammu region since the dry Kandi areas of this region have the potential for sustaining Jatropha plantations. In the state, it is usually grown as a hedge crop around agricultural fields and is under trial plantation in districts like Jammu, Samba, Kathua, Reasi, Udhampur, Rajouri, Doda (Fig. 1, 2). Insect pests have been recorded to be one of the chief limiting factors in the successful cultivation of the crop. Detailed work on the insect pests of this crop was not attempted in Jammu region earlier and only few isolated reports are available from rest of the country $[2,7,14,15]$. 


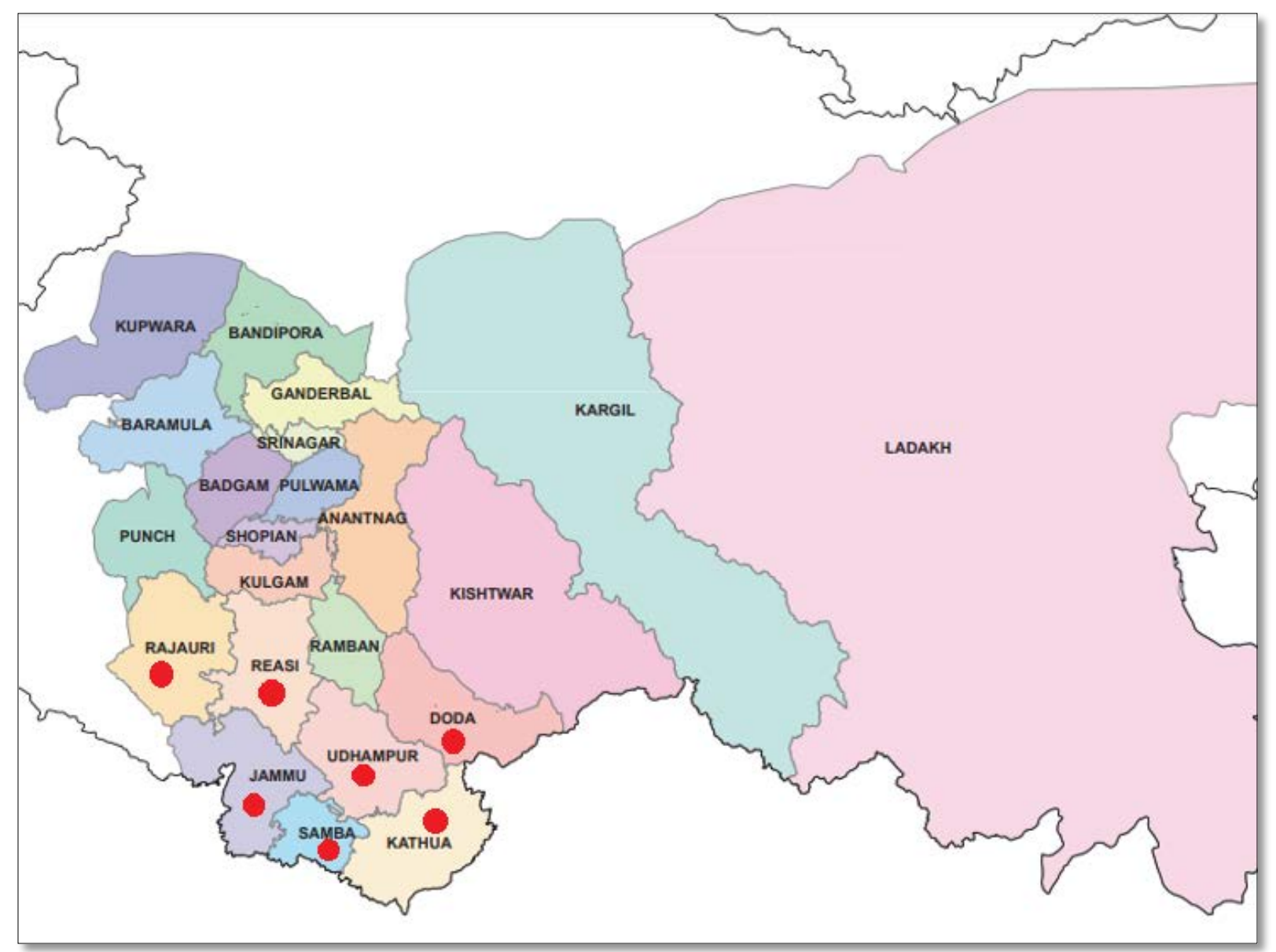

Figure 1. Study Area

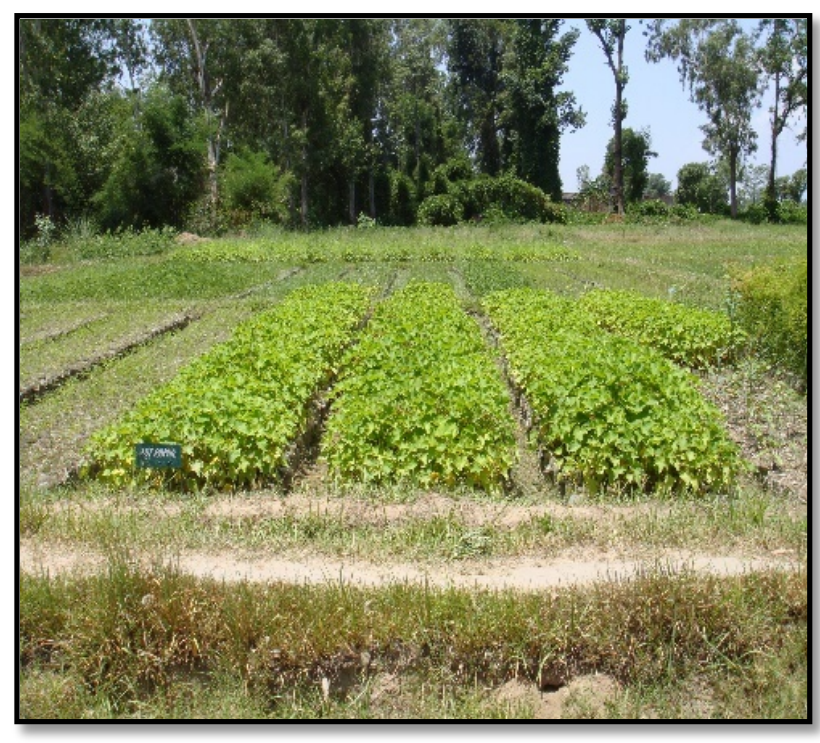

Figure 2. Jatropha Curcas L. (Host Plant)

Although toxic extract of the plant has strong insecticidal properties that is deterrent for insects but contrary to this, several groups of insects have overcome this barrier. A global list of phytophagous insects consisting of 60 species in 21 families and 4 orders have been compiled in Australia, where it is considered as a weed [14]. Insect order Heteroptera cause sufficient damage to this plant. 15 species of Heteropteran insects were reported in Nicaragua to cause extensive damage to it [5]. A total of 49 species of Heteroptera were reported to found on Jatropha plantations in Nicaragua and Cape Verdean [4].

In Jammu, the production of Jatropha curcas is hampered by few Hemipteran insects, of which Scutellera nobilis is found to be very serious. Hence, this study was undertaken with a purpose to assess the life cycle stages and damage, which can later be used to design preventive techniques.

\section{Materials and Methods}

\subsection{Study Area}

Jammu and Kashmir is one of the largest states of the Indian union covering an area of 2, 22,236 Sq. Km. The state lies between $32^{\circ} 17^{\prime}$ to $36^{\circ} 58^{\prime}$ north latitude and $73^{\circ}$ $26^{\prime}$ to $8^{\circ} 30^{\prime}$ east longitude. The state is divided into three 
divisions - Kashmir, Jammu and Ladakh. The present study has been carried out in Jammu division.

\subsection{Jammu Division}

It lies between longitude $74^{\circ} 9^{\prime}$ east and latitude $32^{\circ} 67^{\prime}$ north, situated at the northwest of India bordered by Punjab and Himachal Pradesh in east, Pakistan in the west and south while Pir Panjal range of mountains separates it from Kashmir division in the north. Altitude varies from nearly $1000 \mathrm{ft}$ above the sea level to about $1200 \mathrm{ft}$ from the same. Due to these extreme variations within a limited distance, there is a marked difference in climate. It is divided into ten districts, i.e. Jammu, Samba, Kathua, Udhampur, Reasi, Doda, Kishtwar, Ramban, Rajouri and Poonch (Fig.1).

\subsection{Methods}

Various aspects of biology, life cycle and ecology of Scutellera nobilis were studied at Jammu both in the field as well as in the laboratory. Adult bugs and their immature stages were collected from the field plantations and were released into rectangular insect rearing cages to observe their development under laboratory conditions. A mating pair of adult was released in three replicas in each cage having tender shoots and unripe fruit of Jatropha (dipped in water contained in conical flask to avoid drying of leaves and fruit) for recording the precopulatory behavior, pairing, copulation and oviposition. Eggs laid by insects in cages were kept in petridishes for recording the incubation period. Hatched nymphs were transferred to fresh shoots and unripe fruit and nymphal duration based on moultings was recorded. Newly hatched nymphs were reared individually in glass vials. Each nymph was examined daily to see the molting, which was confirmed by the presence of exuviae.

\section{Observations and Discussion}

Scutellera nobilis commonly known as six-spotted jewel bug has been recorded to be a major threat to Jatropha curcas plantations in Jammu. This bug has been recorded for the first time on Jatropha from Jammu region. However, this bug has earlier been recorded to be distributed in northern India, recently, first report on the presence of this insect pest was reported on Aonla from Gujarat [12]. It is also known to infest grape fruit in Punjab [16]. Besides, it has also been reported from Pakistan, Burma and Siam. Damage caused by this pest on Jatropha was studied by various workers from various parts of the country $[2,7,14,15]$.

Nair reported its presence on grapes, star gooseberry and cotton [9]. Schaefer and Panizzi reported it to be a pest of gooseberry, Phyllantus distichus in India [13]. Meshram and Garg reported it to be a pest on Emblica officinalis damaging the fruit of the plant [8]. Khokhar and Khokhar studied the diagnostic features, body colouration, morphometries of important taxonomic characters of Scutellera nobilis associated with cotton plant in Haryana and adjoining areas [6]. This species has attracted much attention because of its potential to damage the fruit and seeds of the biodiesel plant thus limiting its oil production capability.

Adult: The adult is metallic green in colour with 6 - 8 spots on elytra and 2 spots on scutellum and a longitudinal black streak starting from prothorax and extending up to middle of the elytra (Fig. 3). Body length ranges from $16 \mathrm{~mm}-21 \mathrm{~mm}$ and width from 7 - 9mm. Female bugs are usually larger in size than males and measures between 19 $21 \mathrm{~mm}$ in length to $8-9 \mathrm{~mm}$ in width whereas male bugs measure about 16 - 18mm in length and $6-7 \mathrm{~mm}$ in width. Antennae five segmented, hairy; eyes brown, prominent; tibia and tarsus metallic green in colour; basal segments dark reddish yellow.

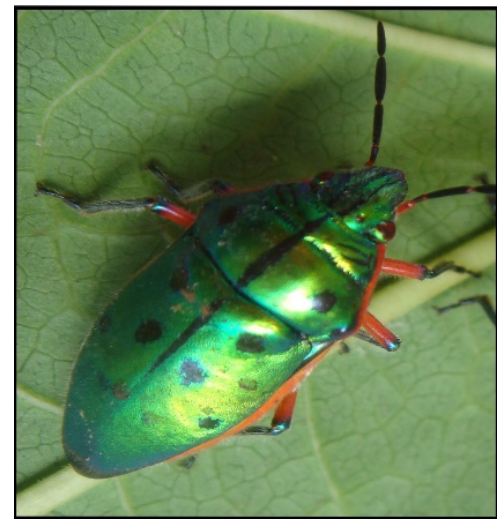

Figure 3. Adult

Eggs: The Eggs are barrel shaped measuring about $2 \mathrm{~mm}$, slight yellow in colour when freshly laid, later becomes red and gradually turns bright red prior to hatching. Eggs are laid in a characteristic pattern in two longitudinal rows, usually 47 - 52 eggs, glued to one another on under surface of leaves, on stem or fruit (Fig. 4).

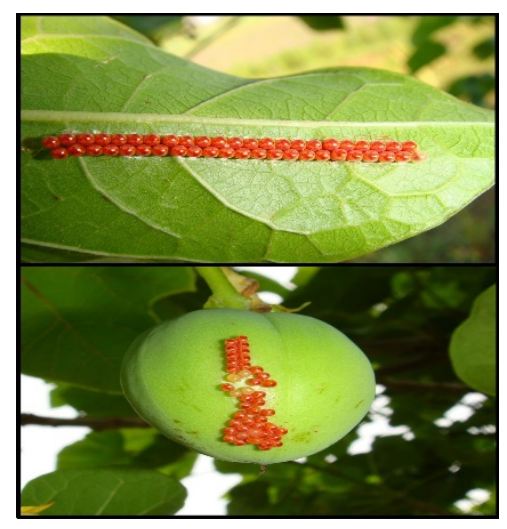

Figure 4. Eggs on leaf and fruit

\subsection{Nymphal Instars}

First Instar: Neonate nymphs are reddish orange in 
colour and measure about 2-2.5 mm. When emerged, they aggregate near hatched eggs till next moult occurs after 3 days (Fig.5).

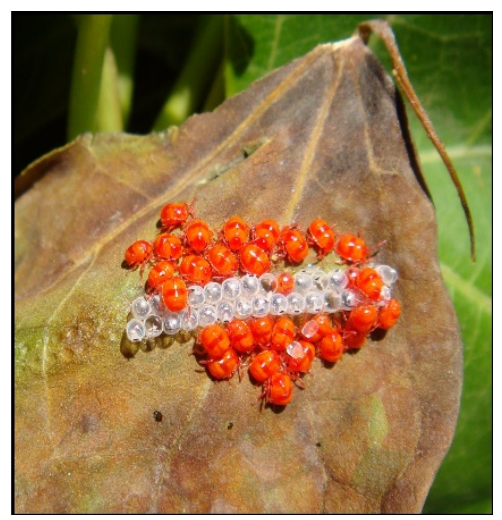

Figure 5. $1^{\text {st }}$ Instar

Second Instar: Freshly moulted nymph is orange red in colour (Fig. 6) later the colour changes to brownish black with transverse black bars on abdomen. Proboscis of nymph is fully developed and extends below its abdomen. They disperse and suck sap from leaves and fruit of the plant. Prior to moulting, they again congregate and moult in aggregation (Fig. 7).

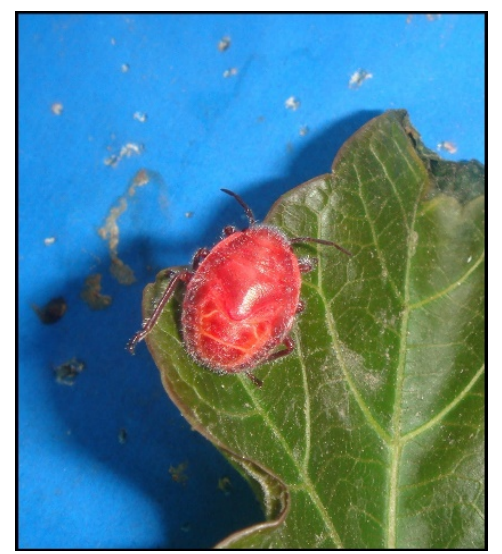

Figure 6. Early $2^{\text {nd }}$ Instar

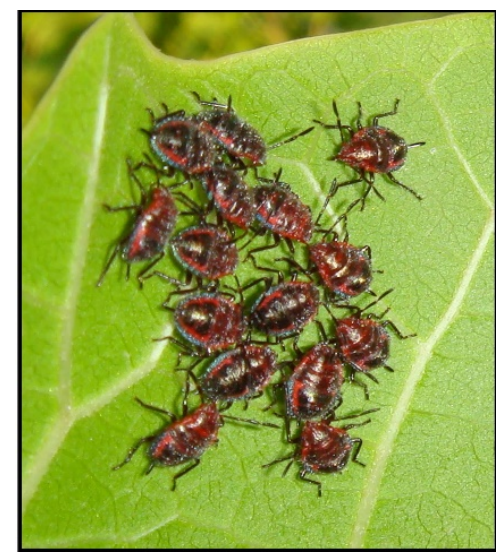

Figure 7. Late $2^{\text {nd }}$ Instar
Third Instar: It is brown coloured nymph with abdomen orange in flanks and 2 thick black bands in middle, feeds on sap extracted from fruit, leaves, and moult to next instar in aggregation (Fig. 8).

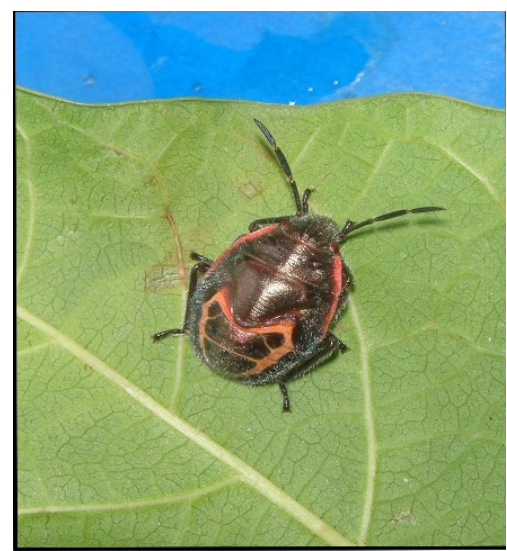

Figure 8. $\quad 3^{\text {rd }}$ Instar

Fourth Instar: It is similar to $3^{\text {rd }}$ instar except in size, being larger in size than the previous instar with reddish orange coloured abdomen with 2 thick black bands. It feeds actively on the fruit, dried seeds, and undergoes moulting to next instar usually in groups (Fig. 9).

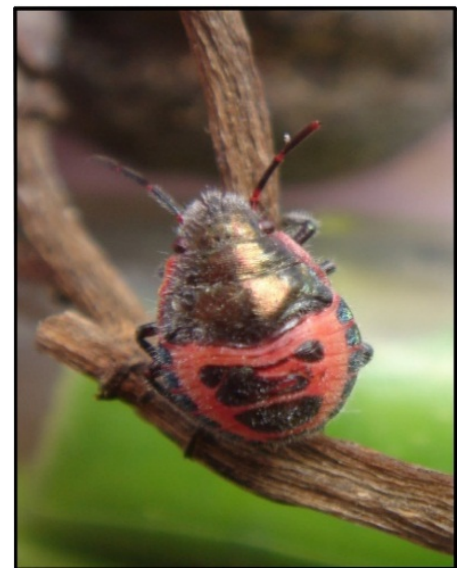

Figure 9. $4^{\text {th }}$ Instar

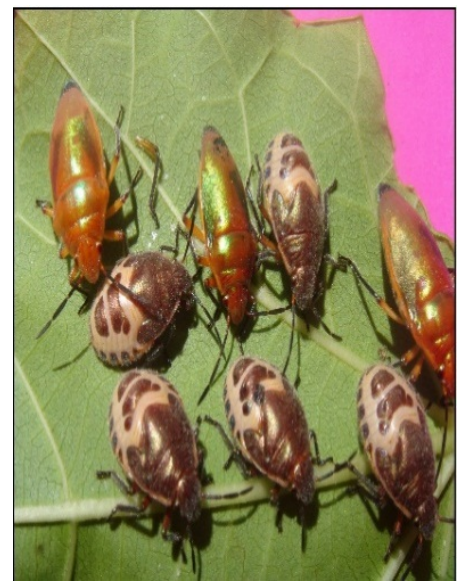

Figure 10. $5^{\text {th }}$ Instar 
Fifth Instar: Final instar of Scutellera nobilis is similar in morphology to the $4^{\text {th }}$ instar but larger in size with creamish abdomen with three thick black bands. They congregate to metamorphose into adults (Fig. 10). Along with adults, they cause extensive damage to fruit and seeds of the plant. Young instars (first to third instars) body size ranges between $2 \mathrm{~mm}$ to $7.5 \mathrm{~mm}$ in length and 2-5 $\mathrm{mm}$ in width and that of later instars (fourth to fifth) ranges between $10 \mathrm{~mm}$ to $13.50 \mathrm{~mm}$ long and 7.5 - $8.5 \mathrm{~mm}$ wide.

\section{Life Cycle and Associated Studies}

Seasonal Availability: Mating pairs were observed from April till November in field conditions with a peak in monsoon season (June - August).

Pre-copulatory Behaviour: The bugs showed no special precopulatory behaviour. Just approaching each other and initial body contact appears to be the stimulus. Adult pairs remain in vicinity of one another for some time and mating process starts (Fig. 11).

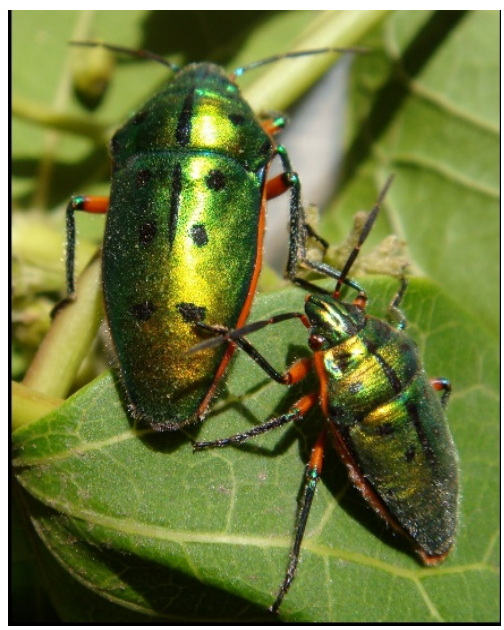

Figure 11. Pre-copulation

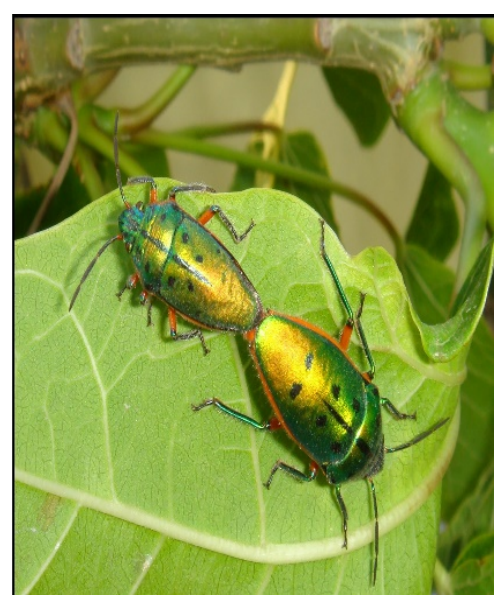

Figure 12. Copulation

Pairing and Copulation: Adults copulate in an end-to-end position and keep on moving from one twig or branch to another (Fig. 12). Observations show that slight disturbance does not hinder the process of mating but the mating pair move rapidly away from source of disturbance. Mating duration was found to last as long as 1 - 2 hours and copulatory pairs were seen from morning till evening in the field. Mating pairs were observed from month of April till late November in field conditions with a peak in monsoon season. Reference [2] recorded a premating period of 1 - 2 days and mating period of 30 - 35 minutes in one of the studies carried out in Tamil Nadu, India.

Preovipositional Behaviour: Mated female patrol, wander around the twigs, leaves of the plant in order to select a suitable site for oviposition, and also feeds on the fruit of the plant. Pre - ovipositional period varies from 5 6 days after which it lays egg on a selected site. Reference [2] recorded a pre - ovipositional period of $4-7$ days in Tamil Nadu.

Oviposition: After selection of ovipositional site, female lays eggs in two longitudinal rows, glued to one another on under (ventral) surface of leaves usually but also on twigs or on fruit surface (Fig. 4). In winter months, when plant is leafless, eggs are laid on stem and branches also. Number of eggs in a batch varies in number from 47 . 52 in laboratory conditions. Each female lays egg in a single batch under the laboratory conditions.

Incubation: Eggs take about 5 - 6 days to hatch and all eggs in a batch usually hatch concurrently. When freshly laid, the chorion of the eggs is slight yellow in colour which later changes to red in due course of incubation and prior to hatching, colour of chorion changes to bright red (Fig. 4). An incubation period of 5 - 7 days was recorded in Tamil Nadu [2].

Hatching: All the eggs in a batch usually hatch concurrently and neonate nymphs congregate near the hatched eggs and are highly gregarious in nature (Fig. 5).

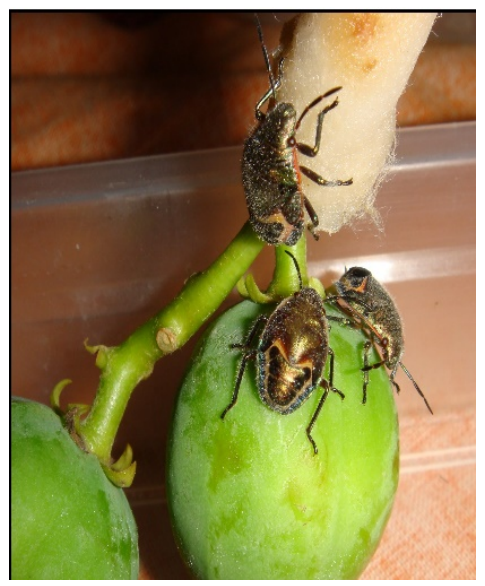

Figure 13. Nymphs Feeding

Post-Hatching Behaviour of Nymphs: After hatching, $1^{\text {st }}$ instar usually feeds in congregation near the hatched eggs. Later instars however feed in smaller groups or disperse feeding in vicinity of adults but prior to moulting; nymphs aggregate together and moult in groups. Nymphs 
( $2^{\text {nd }}$ to $5^{\text {th }}$ ) feed actively and suck sap from leaves, fruit and seeds of the plant (Fig.13).

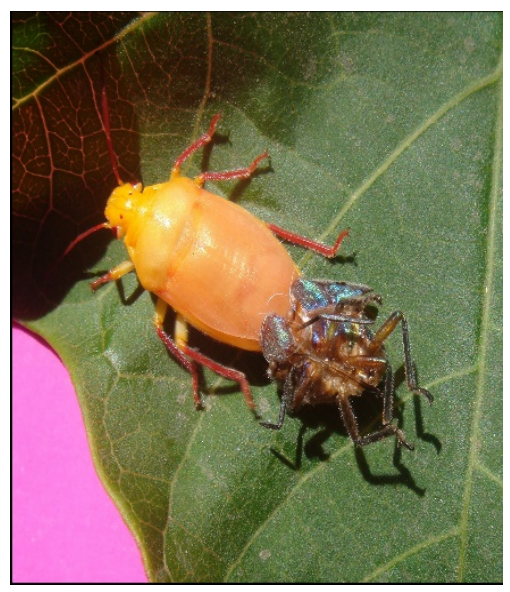

Figure 14. Newly emerged adult

Nymphal Duration: Scutellera nobilis undergoes 4 moults and 5 nymphal instars are recognized (Fig.5-10). The total nymphal duration from $1^{\text {st }}$ to $5^{\text {th }}$ instar is $25-30$ days.

Adult Emergence: Newly emerged adult is reddish orange in colour (Fig. 14). After $1 / 2 \mathrm{hr}$ of emergence, the pigmentation and hardening of elytra starts and pigmentation process continues for 24 hours and the adult is formed (Fig. 3).

Total Life Cycle Duration: Total life cycle duration varies from 30 - 36 days (Table- 1; Fig. 21). Total life cycle duration of 28 - 35 days was observed in Tamil Nadu [2].

Table 1. Life cycle Duration of Scutellera nobilis on Jatropa curcasin Jammu Region

\begin{tabular}{|l|l|}
\hline Life Cycle Stage & Duration \\
\hline Mating Period & $1-2$ hrs \\
\hline Pre-Oviposition Period & $5-6$ days \\
\hline Incubation Period & $5-7$ days \\
\hline Nymphal Instar & Duration \\
\hline First Nymphal Instar & 3 days \\
\hline Second Nymphal Instar & $5-6$ days \\
\hline Third Nymphal Instar & $5-7$ days \\
\hline Fourth Nymphal Instar & $6-7$ days \\
\hline Fifth Nymphal Instar & $6-7$ days \\
\hline Total Nymphal Duration & $25-30$ days \\
\hline Total Life Cycle Duration & 30-36 days \\
\hline
\end{tabular}

Mode of Feeding: Both, the adults and the nymphs, feed voraciously on Jatropha curcas and cause significant damage to the plant. Bug with its piercing mouthparts and sharp and elongated proboscis extract sap and juices from fruit, seeds and leaves (Fig.15). Feeding was observed on fresh as well as dried fruit and seeds as the nutrient content of the fruit and seeds are high and thus provide nutrition to the bugs all through the year. Adults cause maximum damage to fruit and seeds thereby lowering their commercial value.

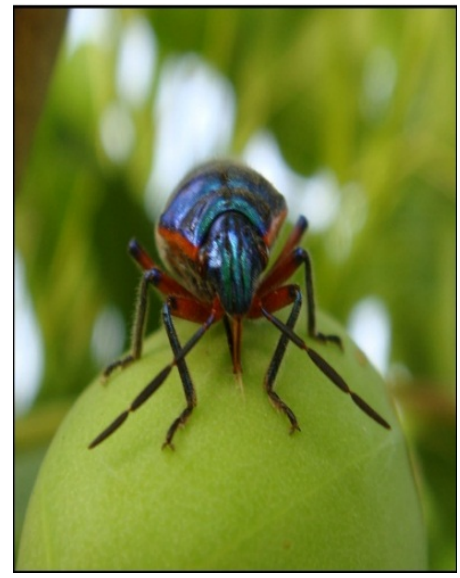

Figure 15. Adult feeding on fruit

Extent of Damage: Due to excessive feeding by adults as well as nymphs of Scutellera nobilis, plant suffers from extensive damage. All plant parts are likely to be fed upon, but growing shoots and developing fruit are preferred. Feeding by bugs causes fruit abortion resulting in the production of malformed and hollowed seeds. The puncture marks on fruit cause drying of fruit, leads to necrosis of the fruit, and ultimately ends in its premature fall and development of hollowed seeds (Fig. 16). The damage caused by punctures made by bug is in the form of dark black spots. These punctures affect the fruit quality that gradually leads to rotting of fruit and the young pods shrivel without producing seeds or produce hollow seeds and decidedly lower its market value (Fig. 17, 18, 19). Extensive feeding by the bugs on the leaves leads to necrosis and gradually to premature leaf fall (Fig. 20). Plant leaves also get shrivelled and bug punctures cause yellowing of leaves and thus limiting its production and growth. In case of heavy infestations and particularly in the young plants, damage by the bugs leads to stunted growth and sometimes cause die back in the plantations in the nurseries.

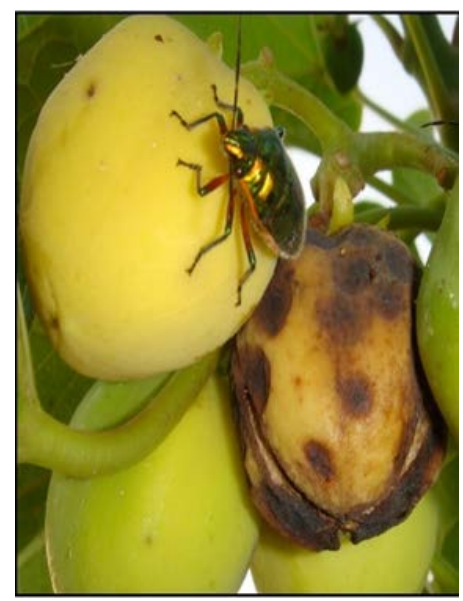

Figure 16. Damage on fruit 

Jatropha curcas L. in Jammu (J\&K), India

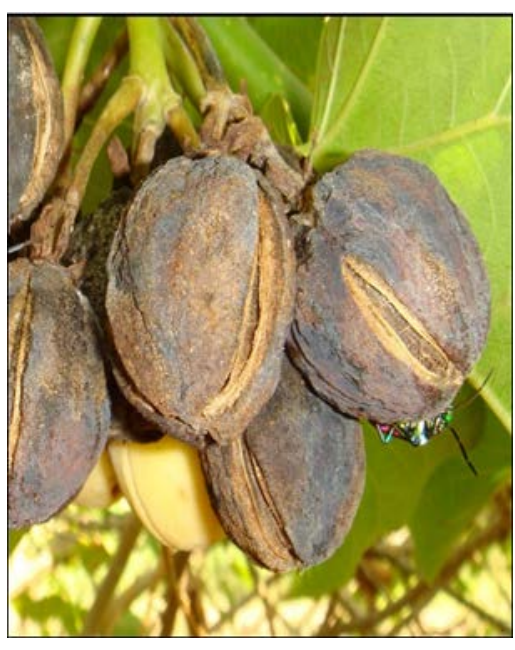

Figure 17. Shrivelled fruits

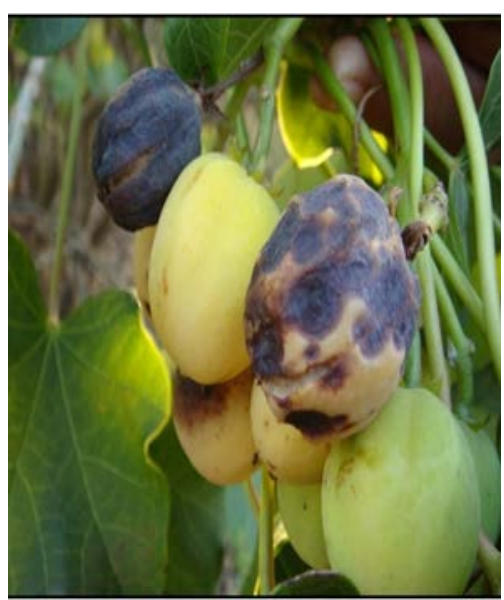

Figure 18. Fruit necrosis

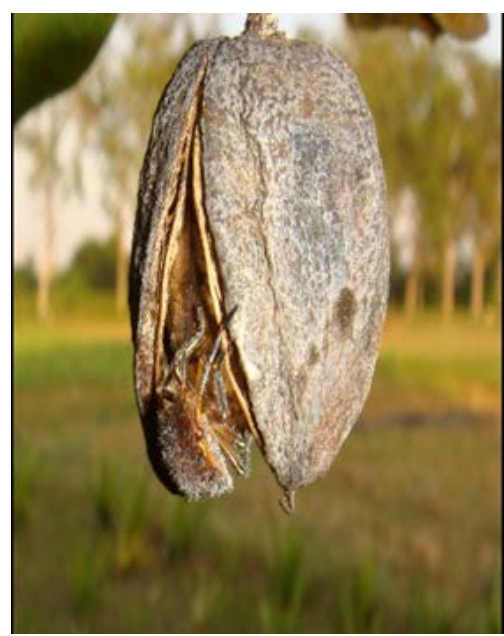

Figure 19. Damaged fruit

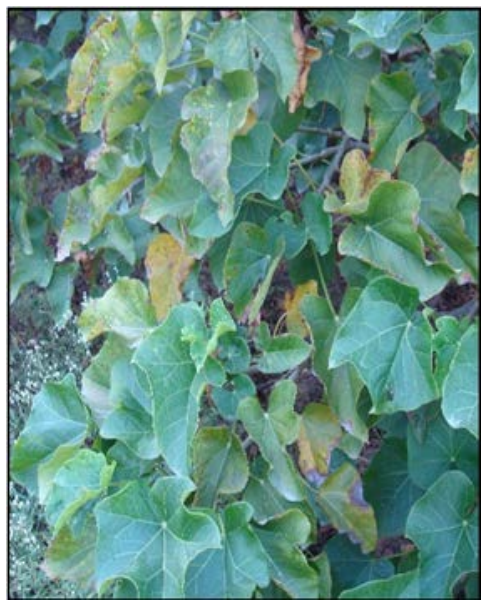

Figure 20. Leaf necrosis 


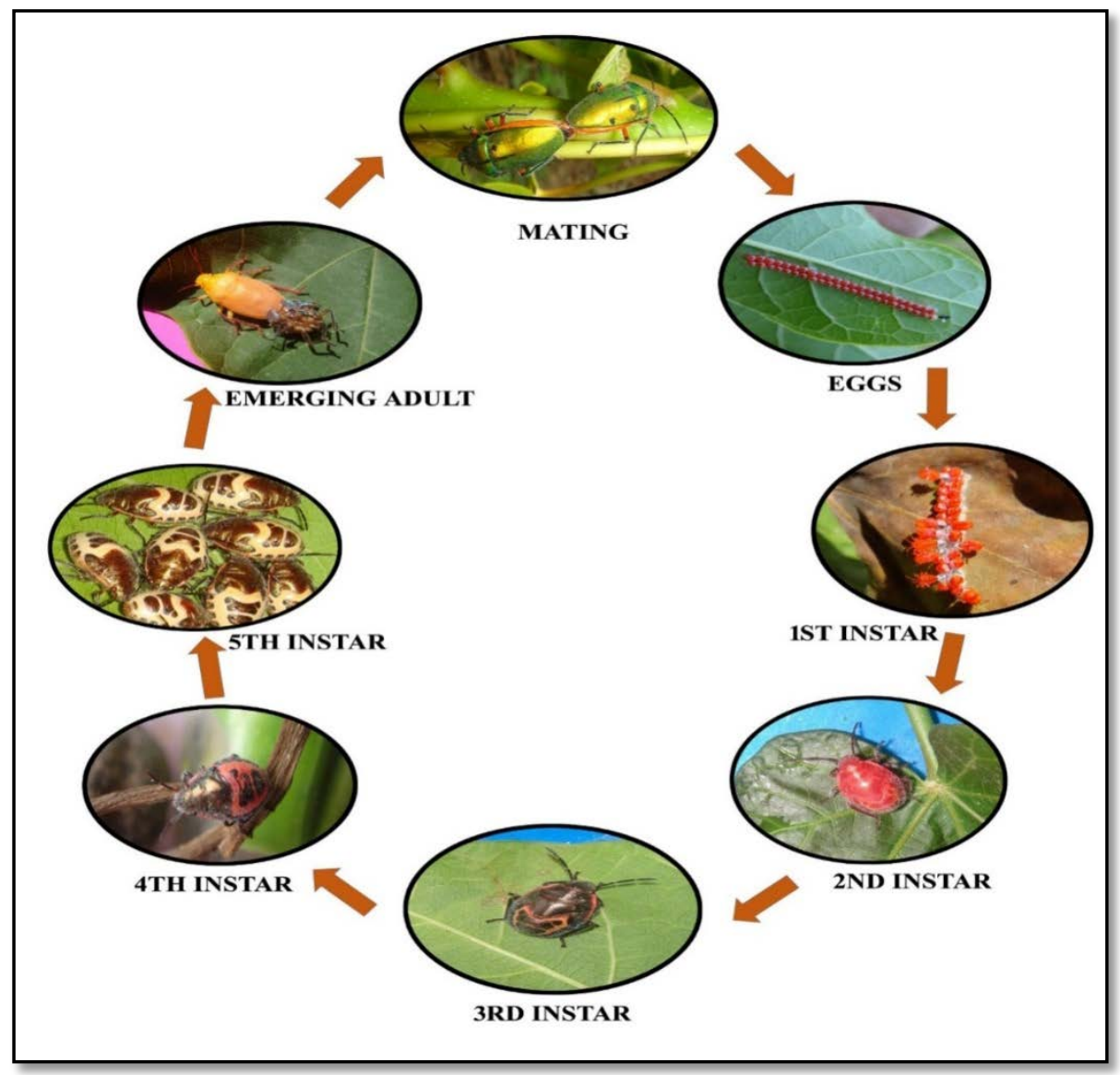

Figure 21. Life Cycle of Scutellera nobilis on Jatropha curcas (L.)

\section{Conclusions}

The present study clearly indicated that Scutellera nobilis is a major hemipteran insect pest of Jatropha curcas L. that has led to decrease in the oil yield by the plant and further, has led to premature leaf and fruit fall. This study revealed that the duration of the life cycle of this pest lasted for 30-36 days. This information can be utilised to design management techniques in order to decrease the pest population, targeting any of the life cycle stages.

\section{Acknowledgements}

Authors are thankful to the Head, Department of Zoology, University of Jammu for providing all the necessary facilities during the course of this work. The authors are thankful to University Research Scholarship (URS) for funding the research.

\section{REFERENCES}

[1] Abobatta, W.F. Jatropha curcas: an overview. Journal of Advances in Agriculture, 10: 1650-1656, 2019.
[2] Ambika, S., Manoharan, T., Stanley, J. and Preetha, G. Scutellarid pests of Jatropha and their management. Annals of Plant Protection Sciences, 5(2): 370 - 375, 2007.

[3] Grass, M. Jatropha Curcas L.: Visions and Realities. Journal of Agricultural and Rural Development in the Tropics and Subtropics, 110(1): 29-38, 2009.

[4] Grimm, C. and Fuhrer, E. Population dynamics of true bugs (Heteroptera) in physic nut (Jatropha curcas) plantations in Nicaragua. Journal of Applied Entomology, 122 (9-10): 515 $-521,1998$.

[5] Grimm, C. and Maes, J.M. Arthropod fauna associated with Jatropha curcas Linn in Nicaragua. A synopsis of species, their biology and pest status. In: Biofuel and Industrial Products from Jatropha curcas. Gubitz, G.M., Mittelbach, M. and Trabi, M. (eds.) Symposium on "Jatropha 97” held on February 23 - 27, Managua, Nicaragua, 1997.

[6] Khokhar, K. and Khokhar, K.S. Biosystematic and biometric studies of pentatomid bugs (Hemiptera: Pentatomidae) associated with cotton. Journal of Arid Legumes, 2(2): 215-219, 2004

[7] Manoharan, T., Ambika, S., Natarajan, N. and Senguttuvan, K. Emerging pest status of Jatropha curcas L. in South India. Indian Journal of Agroforestry, 8(2): 66 - 79, 2006.

[8] Meshram, P.B. and Garg, V.K. A report on the occurrence of Scutellera nobilis Fab. On Emblica officinalis Gaertn. Indian Forester, 125(5): 536, 1999. 
[9] Nair, M.R.G.K. Insects and mites of crops in India. ICAR, New Delhi. India. 1975.

[10] Openshaw, K. A Review of Jatropha curcas: An oil plant of unfulfilled promise. Biomass and Bioenergy, 19: 1-15, 2000.

[11] Parawira, W. Biodiesel production from Jatropha curcas: A review. Scientific Research and Essays, 5(14): 1796-1808, 2010.

[12] Pathan, N.P., Jaiman, R.S., Patel P.S. and Amin A.U. First report of metallic shield bug, Scutellera nobilis (Fabricus) (Scutelleridae: Hemiptera) on Aonla (Emblica officinalis Gaertn.) From Gujarat, India. Journal of Entomology and Zoology Studies, 7(4): 408-409, 2019

[13] Schaefer, C.W. and Panizzi, A.R. Heteroptera of economic importance. CRC Press, United States, 2000.

[14] Shanker, C. and Dhyani, S.K. Insect pests of Jatropha curcas L. and the potential for their management. Current Science, 91(2): 162 - 163, 2006.

[15] Sharma, T.K. Insect pest on biodiesel plant, Jatropha curcas. Bionotes, 8(4): 103, 2006.

[16] Singh, S. and Kaur G. Incidence of metallic shield bug, Scutellera perplexa (Westwood) (=Scutellera nobilis Fabricus) on grape in Punjab. Pest Management in Horticultural Ecosystems, 21(1): 90-94, 2015. 